\title{
Sedative and analgesic potentials of dexmedetomidine gluconate using constant rate infusion technique in rabbit
}

Sogebi, E. A. O.

Department of Veterinary Medicine and Surgery, College of Veterinary Medicine,

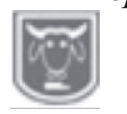

Federal University of Agriculture, Abeokuta. Nigeria

Correspondence: sogebieao@funaab.edu.ng; +2348034481316

\begin{abstract}
Rabbits are easily stressed. Stress can be caused by pain, disease, unfamiliar surroundings, transport, rough handling or proximity of potential predators. Thus, this study was conceived to evaluate the effective sedative and analgesic doses of dexmedetomide gluconate in rabbits using the constant rate infusion (CRI) technique. Eight healthy adult New Zealand White rabbits with an average weight of $1.93 \pm 0.33 \mathrm{~kg}$ were used for the study. They were starved of feed for three hours before the experiment but were supplied water sufficiently. The CRI infusion was prepared by adding $1 \mathrm{mcgkg}^{-1}$ into $500 \mathrm{~mL}$ bags of lactated ringer's solution. Each rabbit received an initial dose of $20 \mathrm{mcgkg}^{-1}$ dexmedetomidine intramuscularly at the thigh muscle. Venous access was secured fifteen minutes later and the fluid prepared for CRI was connected to the cannular, the fluid was set to flow at daily fluid maintenance rate of $90 \mathrm{mlkgday}{ }^{-1}$ for one hour. The procedure was repeated replacing $20 \mathrm{mcgkg} \mathrm{kg}^{-1}$ with $40 \mathrm{mcgkg}^{-1}$. Neither sedation nor analgesia was achieved with $20 \mathrm{mcgkg}^{-1}$ dexmedetomidine ${ }^{\circledR}$ while $40 \mathrm{mcgkg}^{-1}$ gave mild to moderate sedation, however, no analgesic effect was observed with the two dose regimes. In conclusion, sedation was achieved with $40 \mathrm{mcgkg}^{-1}$ but no analgesic effect was achieved in both doses used.
\end{abstract}

Keywords: Analgesic, Continuous rate infusion, Dexmedetomidine ${ }^{*}$, Rabbit, Sedative

\section{Introduction}

Rabbits are small mammals in the family Leporidae of the order Lagomorpha, found in several parts of the world (Wikipedia, 2015). They are small, furry mammals with long ears, short fluffy tails, and strong, large hind legs. They vary in colour and size, ranging from 1 to 7 kilograms d e p e nding o n the bre ed (merckvetmanual.com, 2015). Rabbits are easily stressed. Stress can be caused by pain, disease, unfamiliar surroundings, transport, rough handling or proximity of potential predators such as dogs, cats or ferrets (Flecknell, 1996). Dexdomitor ${ }^{\circledR}$ (dexmedetomidine hydrochloride) is a synthetic alpha2-adrenoreceptor agonist with sedative and analgesic properties (Francisco, 2009). Dexmedetomidine is a potent and highly selective $\alpha-2$ adrenoceptor agonist with sympatholytic, sedative, amnestic, and analgesic properties (Joano and Flavio, 2011). Dexdomitor is indicated for use as a sedative and analgesic agent to facilitate clinical examinations, clinical procedures, minor surgical procedures, and minor dental procedures.It is suitable for sedation and analgesia during perioperative periods: as premedication, as an adjunct for general and regional anaesthesia, and as post-operative sedative and analgesic. Atipamezole chloride Antisedan $^{\circledR}$ ) is the reversal agent of dexmedetomidine.

A constant rate infusion is a dosing regimen used to deliver a constant amount of drug per unit time (Kurt, 2010). The intravenous 


\section{Sedative, analgesic potentials, Dexmedetomidine ${ }^{\circledR}$ CRI Rabbit}

administration of drugs through constant rate infusions allows a consistent blood concentration hence producing analgesia with fewer peaks and troughs with overall lower doses being used, and therefore, fewer side effects (Marieke, 2013).

Very little work has been done on the use of dexmedetomidine in rabbit considering the fact that the use of rabbit in researches, as companion animal and as meat animal is gaining grounds in our contemporary world. This work is aimed at determining the at determining the potential sedative and analgesic potentials of dexmetomidine in rabbit.

\section{Materials and methods}

Eight apparently healthy adult rabbits, sourced from different breeders having an average weight of $1.93 \pm 0.33$ were used for this study. They were acclimatized for three weeks. Each rabbit was fasted food not water for 30 hours before each experiment. A $500 \mathrm{~mL}$ bag of lactated ringer's solution for constant rate infusion was prepared with $1 \mathrm{mcgkghr}^{-1}$ of dexmedetomidine added. An initial loading dose of $20 \mu \mathrm{kg}^{-1}$ of dexmedetomidine was injected intramuscularly through the thigh muscle using a 23guage needle and syringe. A daily fluid maintenance of $90 \mathrm{mlkgday}^{-1}$ was used. The bag of fluid containing dexmedetomidine was connected to the intravenous cannula and allowed to flow at a rate in drops/sec (1 mcgkghr ${ }^{-1}$ of dexmedetomidine) depending on the specific weight of each rabbit. The fluid was allowed to flow for one hour. Each rabbit was monitored continuously for one hour for all the physiological parameters using the patient monitor and records of parameters were taken every 10 minutes. The procedure was repeated replacing a loading dose of $20 \mathrm{mcgkg}^{-1}$ with $40 \mathrm{mcgkg}^{-1}$. The analgesic effect was monitored using the Numerical rating scale (NRS). Values used were heart rate, ventilation, comfort of animal and response to pin-prick at the paw of the hind limb.

\section{Results}

Sedation Rating Scale of $20 \mu \mathrm{g}$ and $40 \mu \mathrm{g}$ of Dexmedetomidine in rabbits is shown in Table 1. The onset of action observed was between 19 to 25 minutes and peak effects were observed after 30 minutes. Sedation was not achieved at loading dose of $20 \mathrm{mcg} / \mathrm{kg}$ in all of the rabbits while mild to moderate sedation was achieved at loading dose of $40 \mu \mathrm{kg}^{-1}$ in 7 of 8 rabbits.

There was difficulty in obtaining the baseline values for the heart rate and pulse rate of rabbits because the rabbits were not comfortable with the electrodes used for taking the heart rate and pulse rate on the multi-parameter patient monitor while they were not sedated.One of the rabbits was observed to exhibit excitement in the course of treatment with the loading dose of $20 \mathrm{mcgkg}^{-1}$.

Table 1: Sedation Rating Scale of $20 \mu \mathrm{g}$ and $40 \mu \mathrm{g}$ of Dexmedetomidine in rabbits

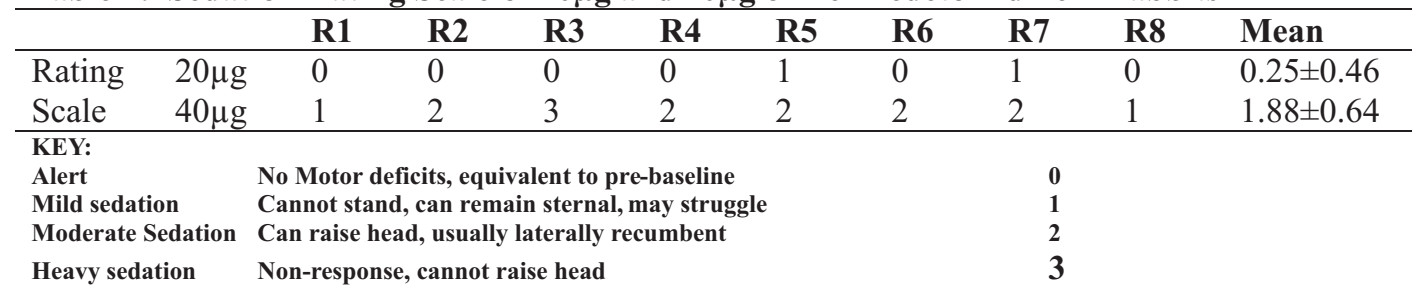




\section{Sogebi}

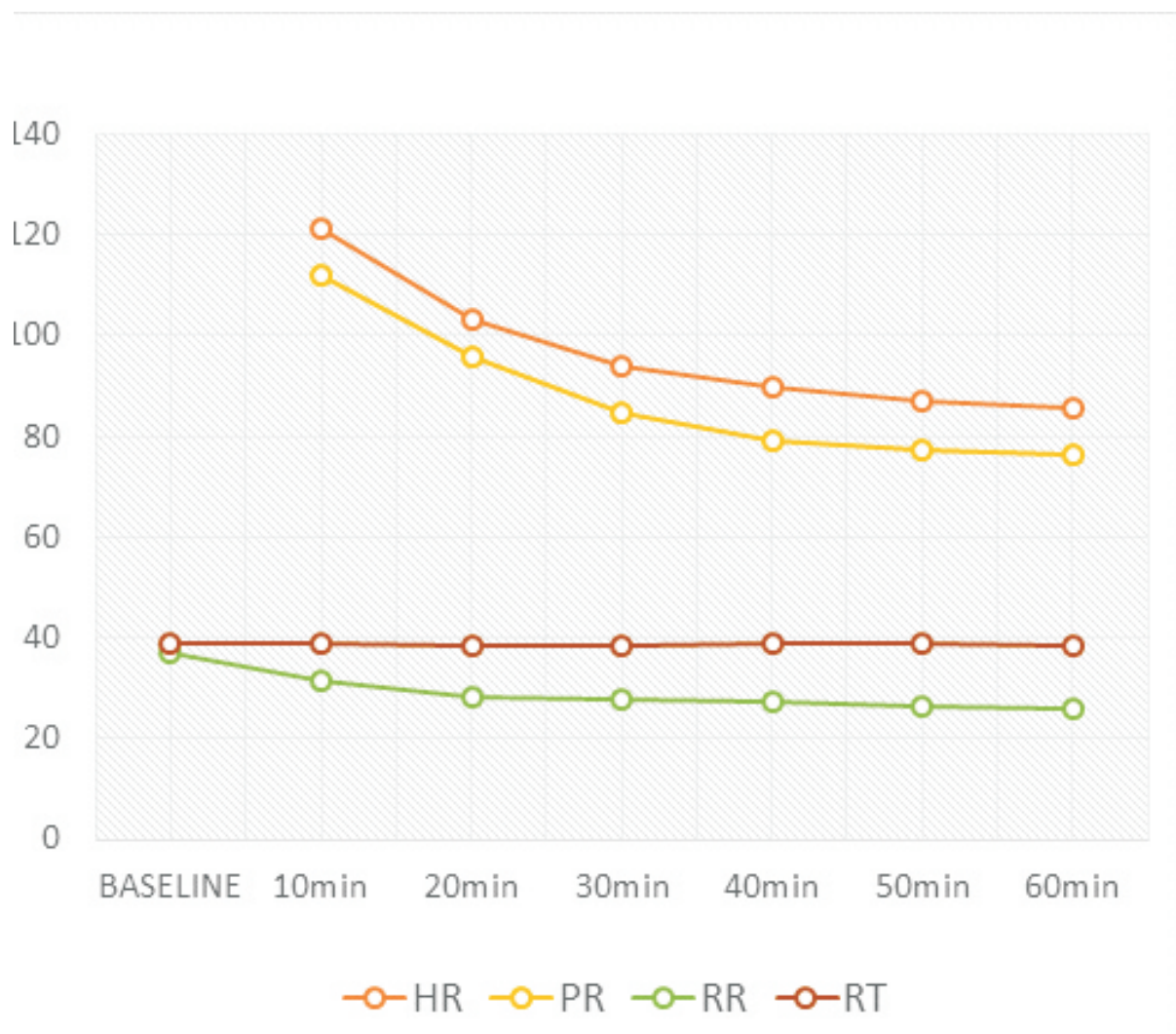

Figure 1: Graphical representation of the mean heart rate (HR), pulse rate (PR), respiratory rate (RR) and rectal temperature (RT).

\section{Discussion}

The onset of action was observed to be between 19 to 25 minutes, this was reflected in the disinterest of the rabbits in their environment, and the progressing of their posture from standing to sternal recumbency. The peak effects were observed after 30 minutes of sedation. Slight to moderate sedation was achieved as reflected in the body posture. The rabbits were either on sternal or lateral recumbency. They try to stand in response to toe pinch but were ataxic. Moderate to deep sedation was observed in cats at $40 \mathrm{mcg} / \mathrm{kg}$ as reported by Mikael et al.
(2006).

The study showed that there was reduction in the heart rate and pulse rate of sedated rabbits. This agrees with the findings of Joano and Flavio (2011), they reported that the drug to have sedative and analgesic effects in dogs and cats. It is observed as shown in Figure 1 that the level of reduction in the heart rate and pulse rate was stronger in the initial 40 minutes post injection. This is thought to be probably due to the initial rise in plasma concentration of the drug after induction. Attainment of steady state due to the constant rate of infusion is also thought to be responsible for the weakened 


\section{Sedative, analgesic potentials, Dexmedetomidine ${ }^{\circledR}$ CRI Rabbit}

reduction in heart and pulse rate.

Slight reduction in the respiratory rate was observed in sedated rabbits. This is also as reported by Joano and Flavio (2011). There was no observable effect on the rectal temperature, this contradicts the report of Mikael et. al. (2006) although significant reduction reported by Mikael et al was observed 90 minutes post injection.

\section{Conclusion}

The study showed that sedation was not achieved with $20 \mathrm{mcg} / \mathrm{kg}$ of dexmedetomidine hydrochloride. Slight to Moderate sedative effect was achieved at $40 \mathrm{mcg} / \mathrm{kg}$ with mild reduction in heart rate, pulse rate and respiratory rate. The initial doses of dexmedetomidine hydrochloride used in this study did not give any analgesic effect.

\section{Recommendation}

More work should be done to determine the most appropriate dose of dexmedetomidine hydrochloride that is required to achieve heavy sedation and analgesia in rabbit to enable intubation.

\section{References}

Drugs.com. 2015. Dexdomitor. www.drugs.com/vet/dexdomitor.h tml Accessed on 2/4/2015

Flecknell, P. A. 1996. Laboratory Animal Anaesthesia.Academic Press. In: $50^{\circ}$ Congresso Nazionale Multisala. Società Culturale Italiana Veterinari per Animali Da Compagnia Rimini, Italia.

Francisco, J. T. 2009. Dexmedetomidine: A New Alpha-2 Agonist for Small Animal Practice. Proceedings of the 34th World Small Animal Veterinary Congress (WSAVA) São Paulo, Brazil.

Gaynor, J. S. and Muir, W. W. 2009. Hows and Whys of CRI Analgesia in Small Animals Handbook of Veterinary Pain Management.Ed. 2. St. Louis, MO, Mosby Elsevier. Pp. 457 - 461

Geraldine, D. 2009. Rabbit Medicine: A basic approach to veterinary care, com on small a n i mal emergencies, and light therapy: holistic treatment of wildlife and rescue animals. Proceeding of Latin American Veterinary Conference, Lima, Peru.

Joano, A. and Flavio, R. 2011. Dexmedetomidine current role in anaesthesia and intensive care. $R e v i e w \quad o f$ BrasilianAnaesthesiology 62 (1) 118-133.

Kurt A. G. 2010. How to make and use continuous rate infusions in private practice (Proceedings). Accessed at

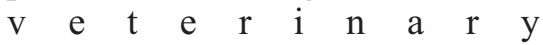
calendar.dvm360.com/how-makeand-use-continuous-rateinfusions-private_practice proceedings on $5 / 02 / 2016$

Liz, W. 2009. Intravenous Access and Fluid Therapy.Anaesthesia for Veterinary Nurses. Ed. Liz Welsh.Blackwell Publishing Ltd. pp. 191-232.London,U.K.: Pharmaceutical Press.

Marieke T. 2013. Analgesia and Anaesthesia: An In Depth Focus on The Latest Sedation Protocols and Modern Techniques for Effectively Managing Pain in Horses. Equine Health. Pp. 5-22

Merckvetmanual.com. 2015. Description and Physical Characteristics of $\begin{array}{lllllll}\mathrm{R} & \mathrm{a} & \mathrm{b} & \mathrm{b} & \mathrm{i} & \mathrm{t} & \mathrm{s}\end{array}$. www.merckvetmanual.com/pethea lth/exotic pets/rabbits/description and physical_characterists of 


\section{Sogebi}

rabbits.html. Accessed on $09 / 15 / 2016$

Mikael, G., Jouni N., Beatrice, C., Iris, R., Eva, L., Arne, A., Gry, Ø., Odd, H., Anna, K. and Serban, U. 2006. Freedom of Information Summary. Supplemental New Animal Drug Application. ( N A D A ) $141-267$. Dexdomitor.Dexmedetomidine Hydrochloride sterile injectable solution cats.

Short, C. E. 1992. Alpha-2-agents in animals - Sedation, analgesia and anaesthesia.Santa Barbara, Veterinary Practice Publishing Company \&Brillig Hill Inc., 1992.
Vainio, O. 1989. Introduction to the clinical pharmacology of medetomidine. A c t a $V e t$ Scand Suppl 85: 85-88.

Wikipedia.org. 2015. Dexmedetomidine. http://en.wikipedia.org/wiki/dexm edetomidine. Accessed on 2/4/2015.

Received: $11^{\text {th }}$ February, 2017

Accepted: $21^{\text {st }}$ June, 2017 